\title{
Ten Year Clinical and Aesthetic Outcomes of an Immediately Placed and Restored Implant in the Anterior Maxilla: A Case Report
}

\author{
Himanshu Arora *(D) and Sašo Ivanovski *(D) \\ School of Dentistry, The University of Queensland, Herston, QLD 4006, Australia \\ * Correspondence: himanshu.arora@uq.edu.au (H.A.); s.ivanovski@uq.edu.au (S.I.); \\ Tel.: +61-7-336-58064 (H.A. \& S.I.)
}

check for updates

Citation: Arora, H.; Ivanovski, S. Ten Year Clinical and Aesthetic Outcomes of an Immediately Placed and Restored Implant in the Anterior Maxilla: A Case Report. Prosthesis 2021, 3, 129-136. https://doi.org/ 10.3390 / prosthesis3020014

Academic Editor: Bruno Chrcanovic

Received: 9 March 2021

Accepted: 29 April 2021

Published: 6 May 2021

Publisher's Note: MDPI stays neutral with regard to jurisdictional claims in published maps and institutional affiliations.

Copyright: (c) 2021 by the authors. Licensee MDPI, Basel, Switzerland. This article is an open access article distributed under the terms and conditions of the Creative Commons Attribution (CC BY) license (https:// creativecommons.org/licenses/by/ $4.0 /)$.

\begin{abstract}
The nature of immediate implant placement followed by an immediate restoration protocol makes it particularly suited to the anterior maxilla. In addition to saving treatment time and avoiding additional surgical procedures, this protocol has been reported to improve aesthetic outcomes by supporting the peri-implant tissues during the implant healing phase through the use of a provisional restoration. This case report documents the use of this protocol in a patient with a failing maxillary anterior tooth and reports on the soft and hard tissue changes over an observation period of 10 years. An implant was immediately placed after removal of a failing maxillary central incisor followed by the provision of a screw retained provisional crown on the same day. A definitive restoration was placed after a 3-month healing period. Not only did this protocol manage to maintain peri-implant bone levels over the 10-year follow-up period, excellent aesthetic outcomes and very limited soft tissue recession were observed with the use of this technique.
\end{abstract}

Keywords: aesthetics; dental implants; immediate placement and restoration; osseointegration; soft tissue

\section{Introduction}

In order to shorten the overall treatment time, protocols such as immediate implant placement have been introduced to expedite the treatment process and minimize the number of surgical interventions [1]. The provision of an immediate restoration at the time of immediate placement (IPR) has been proposed to achieve a better aesthetic outcome by providing support to the peri-implant tissues [2]. This is of considerable importance in the anterior maxilla where aesthetics play a major role in the overall success of an implant supported restoration.

Recent systematic reviews have reported that acceptable clinical and aesthetic outcomes can be achieved following the placement of immediate implants in the anterior maxilla [2-4]. Interestingly, most of the included studies reported outcomes for periods of less than five years. As mentioned previously, tissue in the peri-implant area can undergo changes over the longer term, potentially leading to compromised aesthetic outcomes. The purpose of this case report was to evaluate the soft and hard tissues around a single immediately placed and restored implant in the anterior maxillary region after a follow-up period of 10 years.

\section{Materials and Methods}

A 57-year-old female was referred in August 2009 to a periodontal specialist practice in Brisbane, Australia with a failing upper left central incisor. Upon examination, it was observed that tooth 21 , which was previously root canal treated, had suffered a vertical root fracture and was deemed unrestorable with a hopeless prognosis (Figure 1). 


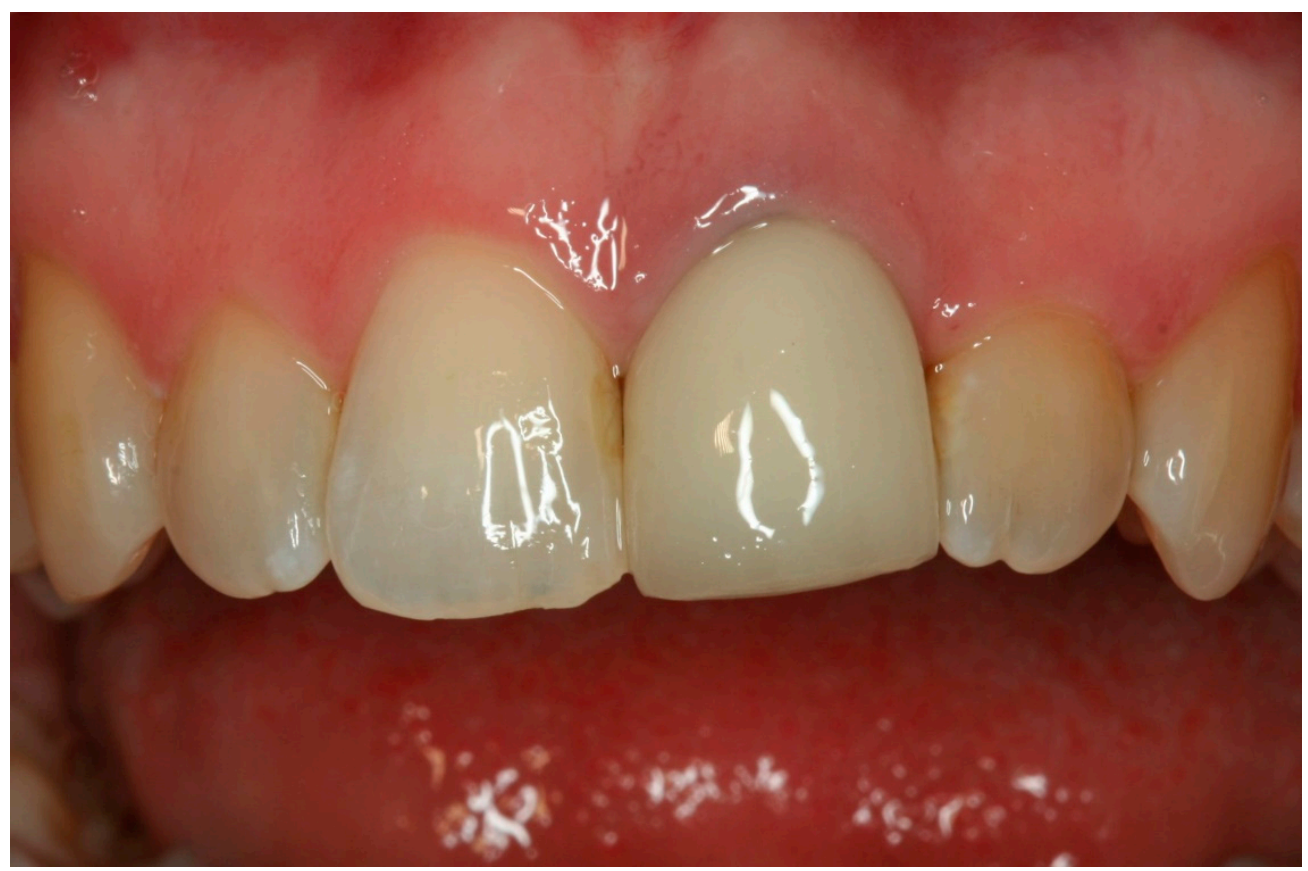

Figure 1. Preoperative presentation: Failing 21.

After a thorough clinical evaluation by a specialist periodontist (SI), it was decided to remove the tooth, followed by the placement of an implant and the provision of an immediate restoration on the same day if some specific criteria were met [5]. These included absence of acute infection around the tooth to be replaced; absence of soft tissue pathology around the gingival margin; absence of any fenestration or dehiscence of the facial socket wall; and achievement of primary stability $>30 \mathrm{Ncm}$.

Prior to the procedure, the patient was given a prophylactic dose of $500 \mathrm{mg}$ Amoxicillin t.i.d to start a day before the surgery. The antibiotic course was continued for 7 days. On the day of the surgery local anaesthesia was administered and the tooth was extracted atraumatically without the elevation of a flap and with the help of a periotome, to prevent any damage to the facial bone around the tooth. After extraction, the socket was thoroughly inspected and cleaned. This was followed by the preparation of an osteotomy according to the manufacturer instructions for the placement of an implant (Astra Tech, Molndal, Sweden). Particular care was taken during the preparation of the osteotomy to facilitate both primary stability and screw retained access while placing the implant in a correct three-dimensional position $[5,6]$.

After placement, a healing cap was secured on to the implant and the gap between the implant and the facial wall (jumping distance) was filled with xenogenic bone graft particles (Bio-Oss, Geistlich Pharma AG, Wolhusen, Switzerland). A screw retained provisional restoration was fabricated using the previous tooth as a template. The provisional restoration was connected to the implant and checked for any interferences in centric occlusion as well as protrusive and lateral movements. The restoration was adjusted until it was clear of any contact in both centric and excursive positions. The emergence profile of the restoration was developed to support the surrounding facial/palatal soft tissues as well as interdental papillae. Finally, the restoration was finished and polished and delivered with the screw access hole closed with a temporary restorative material. Post-operative instructions included advising the patient to avoid biting in the anterior region, avoiding brushing the area around the implant, chlorhexidine rinses twice daily for 2 weeks, Ibuprofen $400 \mathrm{mg}$ for pain control as needed.

Three months post implant placement, the osseointegration was verified by the surgeon, following which the patient was referred to a prosthodontist for final impressions and placement of a definitive restoration. The patient was seen 6 monthly after final restoration 
delivery for the first year and then at yearly intervals. The following time-points were used for evaluation in this case report:

T0-Baseline/Implant placement.

T1-Definitive crown placement.

T2-1-year follow-up.

T3-3-year follow-up.

T4-5-year follow-up.

T5-10-year follow-up.

At each follow-up appointment, peri-implant soft and hard tissues were checked clinically and with the help of radiographs (Figures 2 and 3). Intraoral radiographs were taken with a paralleling technique after implant placement and the various follow-up timepoints. These images were imported to Image J software (Image J 1.43u, NIH, Bethesda, Maryland) to evaluate the changes in peri-implant bone levels. The implant length and the inter-thread distance was used for image calibration and the implant shoulder was used as a reference to evaluate the changes in bone levels over time.

Intraoral photographs were taken with the help of a DSLR camera (Cannon 1300D, Cannon Inc., Tokyo, Japan) at a fixed angle and magnification ratio to evaluate the soft tissue changes around the implant (Figures 2 and 3). A periodontal probe with standardized markings was placed on the adjacent tooth to help in image calibration. The images were imported to Image J where the incisal edges of the adjacent teeth were used to draw a reference line based on which the changes in the papillae and midfacial soft tissue levels were calculated, as described previously [5].

Intraoral photographs were also used to evaluate the aesthetic outcomes, which were assessed using the Pink Esthetic Score [7]. The PES consists of 7 variables, each of which is given a score between $0-2$, with a maximum achievable score of 14 .

At the 10-year follow-up (T5), a CBCT scan as well as an intraoral digital scan (TRIOS, 3Shape, Copenhagen, Denmark) were done to evaluate the soft and hard tissues around the implant. Both scans were imported into an implant planning software (coDiagnostiX, Dental Wings, Montreal, QC, Canada). The intraoral scan was merged with the DICOM data from the CBCT in the software to evaluate the dimensions of the bone and soft tissues around the implant (Figure 4). After merging the intraoral and CBCT data in the software, an implant avatar with make and dimensions similar to the actual implant was imported and superimposed (Figure 5B). Two annotation lines were drawn through the center of the implant longitudinally and the implant platform horizontally. Horizontal measurements were made from the center of the implant to the outer level of bone and soft tissue at 1,3 , and $5 \mathrm{~mm}$ from the implant platform. Vertical measurements were made from the annotation line at the level of the implant platform to evaluate the height of the bone and soft tissue level above the implant (Figure 5C).

Informed consent was obtained from the patient, and the study was approved by the Ethics Committee, University of Queensland, Australia. 


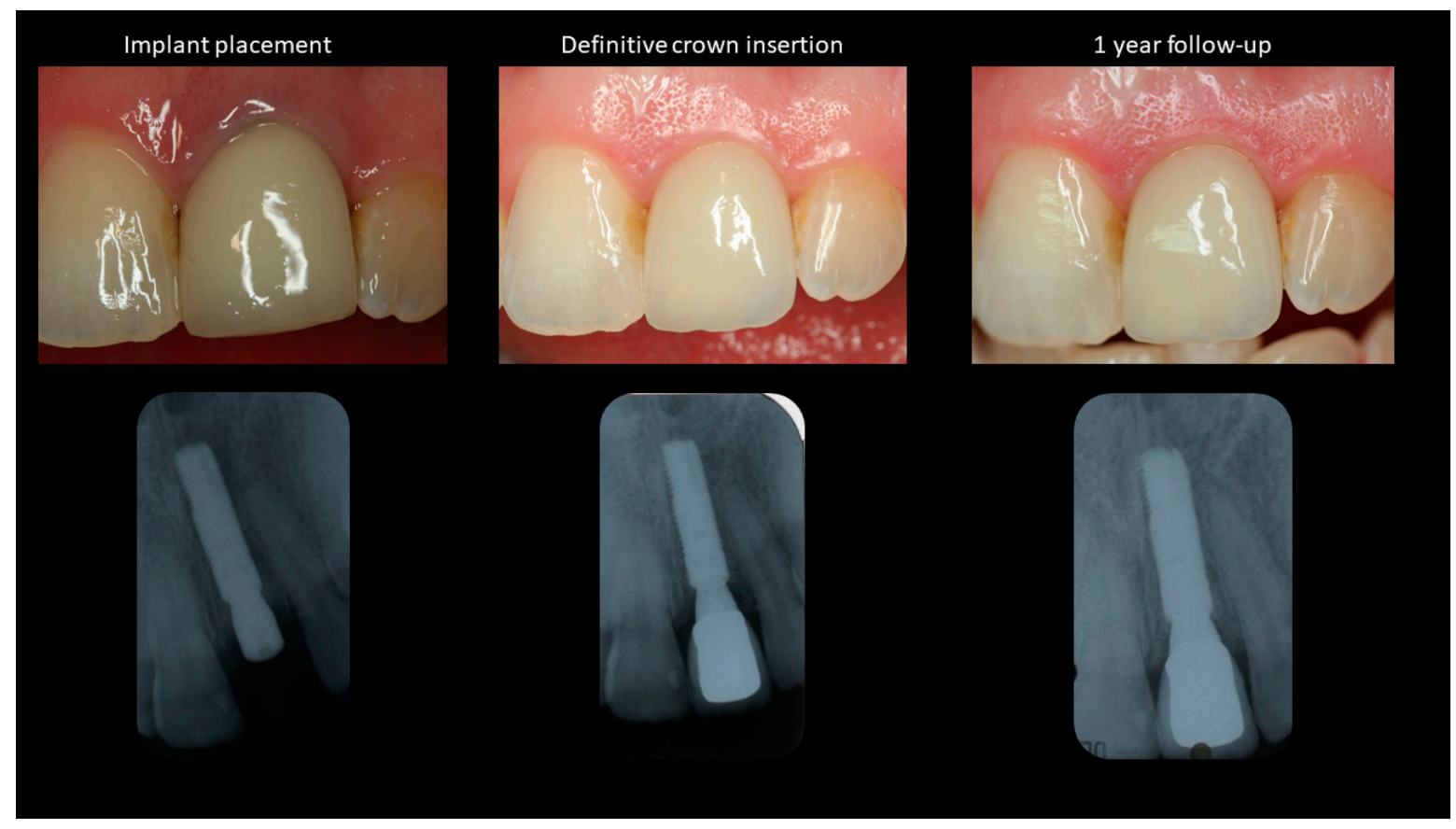

Figure 2. Peri-implant soft and hard tissue levels at implant placement, crown insertion and 1-year follow-up.

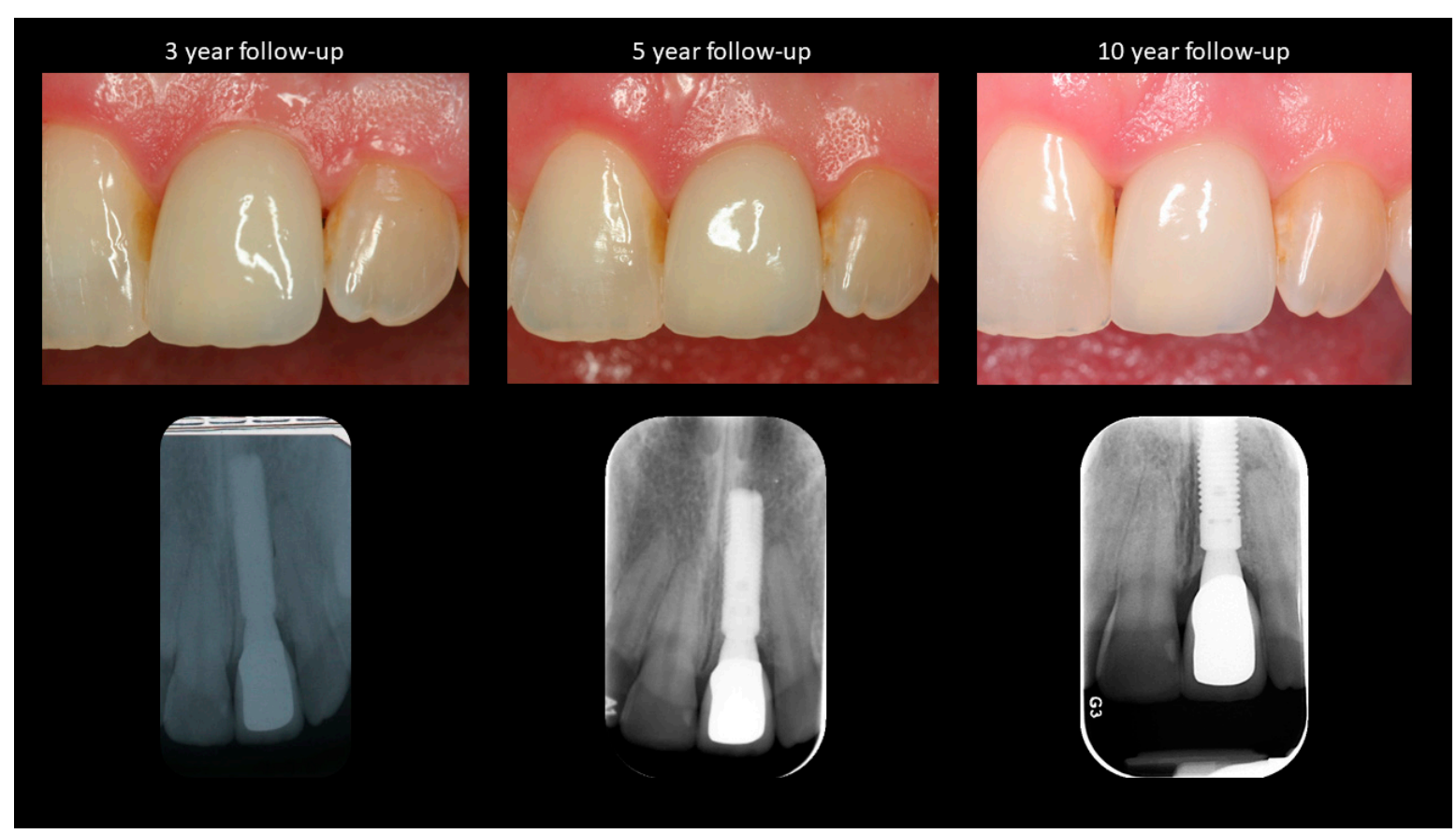

Figure 3. Peri-implant soft and hard tissue levels at 3, 5, and 10 year follow-up appointments. 


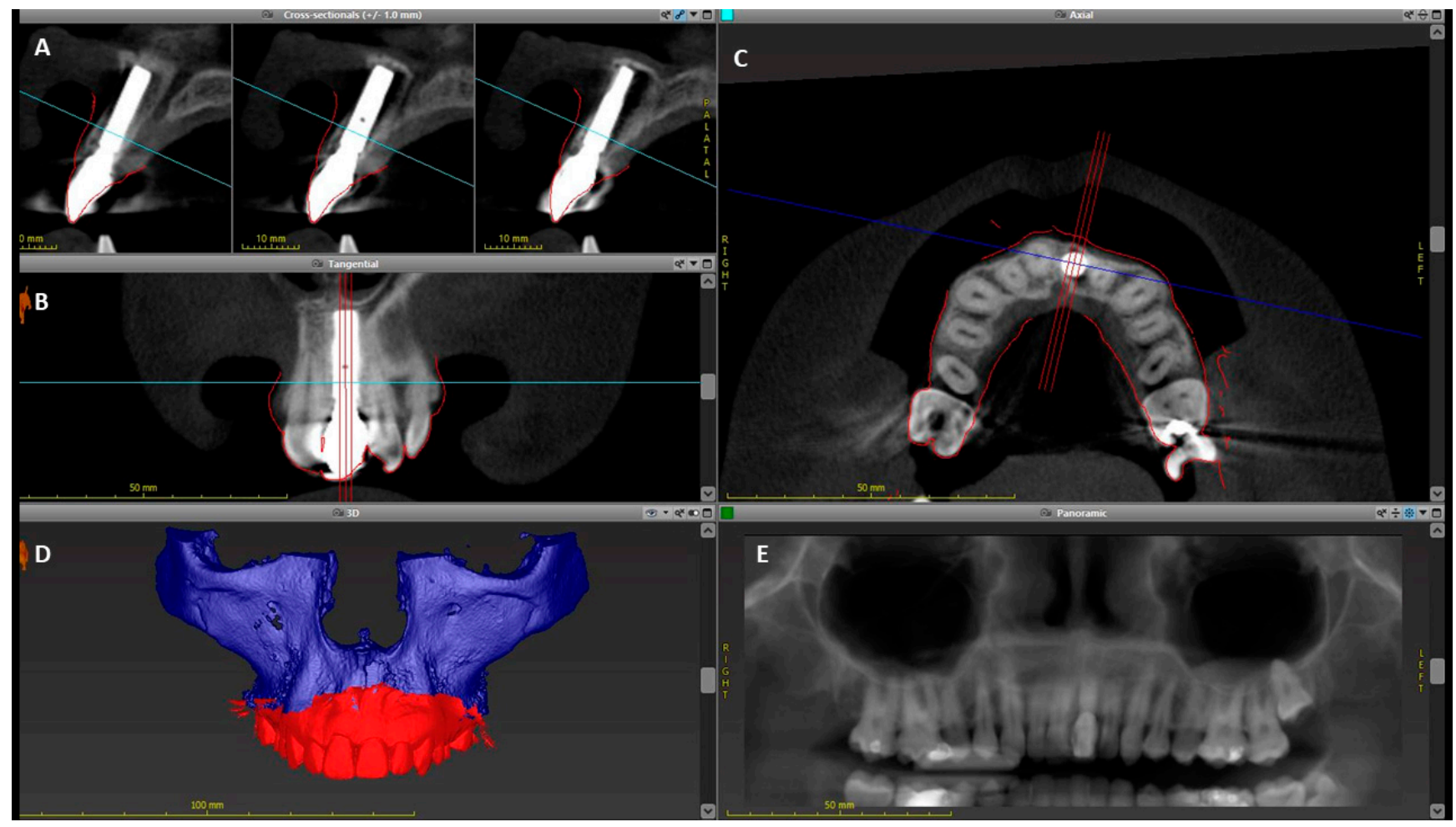

Figure 4. Working screen for the coDiagnostiX software. (A) Implant in cross-sectional view, (B) Implant in tangential view, (C) Implant in axial view, (D) CBCT scan and intraoral digital scan from T5 imported and superimposed using coDiagnostiX software, (E) Reformatted panoramic view.
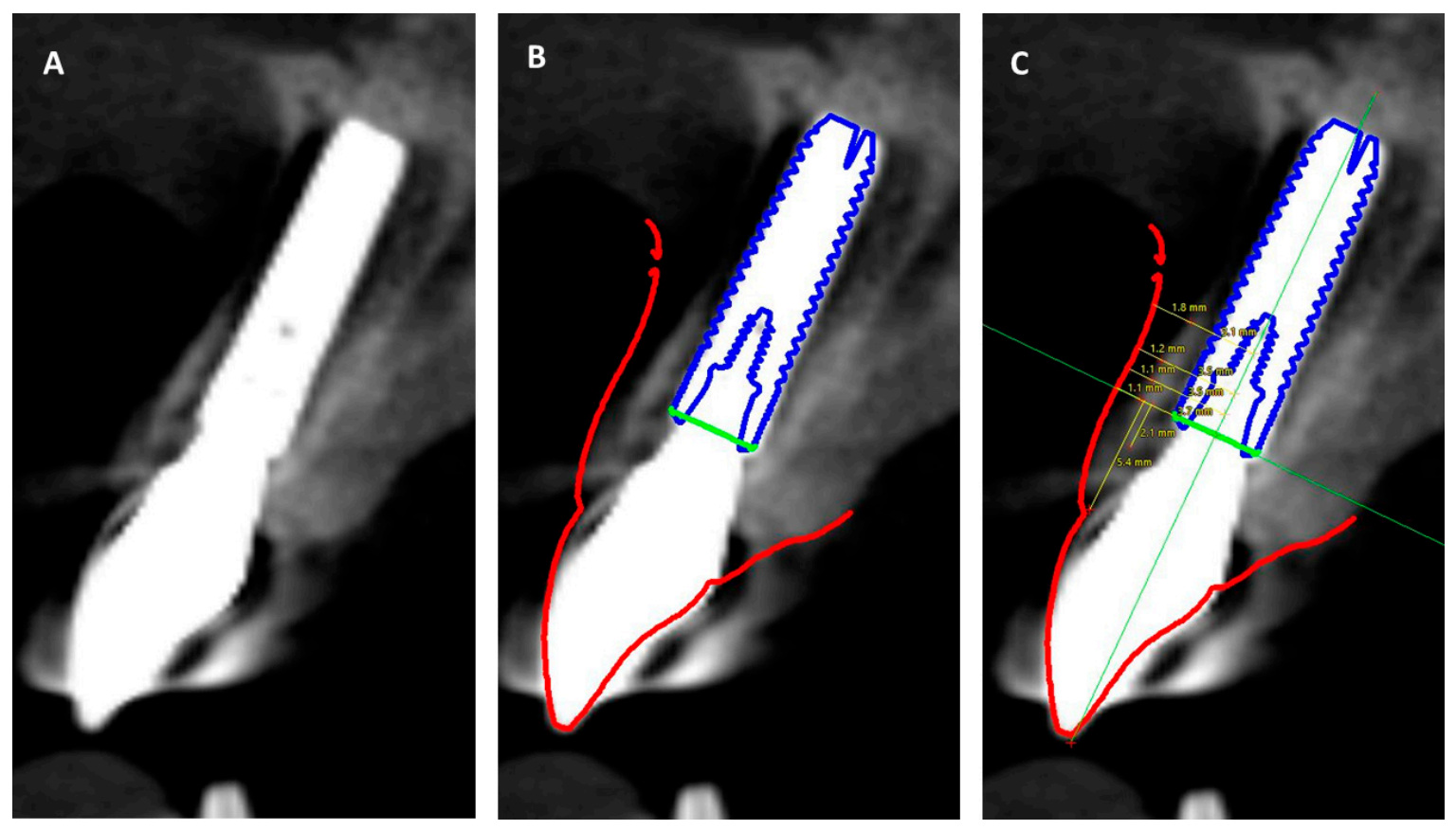

Figure 5. Implant in cross-section view in coDiagnostiX software. (A) Cross-section through the center of the implant, (B) Implant avatar and soft tissue silhouette superimposed on the implant, (C) Vertical and horizontal measurements made using annotation lines to evaluate the thickness and height of soft and hard tissues. 


\section{Results}

An AstraTech TX $4.0 \mathrm{~mm}$ wide and $15 \mathrm{~mm}$ long implant was placed immediately after extraction of tooth 21. An immediate provisional restoration was in place for a period of 3 months before a definitive porcelain fused to metal cement retained crown was placed on the implant. The patient was seen yearly for follow-ups over the period of 10 years. The implant had been functioning well over the 10-year follow-up and no biological or prosthetic complications were observed. Gingival tissues remained healthy and free from bleeding, and no probing depths were reported over $3 \mathrm{~mm}$ at any of the follow-up visits.

Figures 2 and 3 show the clinical photographs and radiographs from baseline (T0) to the final follow-up (T5). A minor gain in the midfacial mucosal margin was observed between implant placement and connection of the definitive crown (Table 1). The midfacial mucosa remained stable after the insertion of the crown to the 10-year follow-up. Mesial and distal papilla levels remained stable between the T0-T4 time points. Although no changes were seen in the distal papilla, a slight change was observed in the mesial papillary level between T4-T5 (Table 1). A slight improvement was observed in the aesthetic outcomes as measured with the help of PES. The overall PES improved from 10 at T0 to 11 at T5.

Table 1. Tissue changes and aesthetic outcomes over the various follow-up time points.

\begin{tabular}{ccccccc}
\hline & \multicolumn{2}{c}{ Soft Tissue Recession (in mm) } & \multicolumn{2}{c}{ Bone Level Changes (in mm) } & PES * \\
\hline & Mesial Papilla & Midfacial & Distal Papilla & Mesial & Distal \\
\hline T0 & - & - & - & - & - & 10 \\
T1 & 0.2 & -0.2 & 0.0 & 0 & -0.2 & 12 \\
T2 & 0.2 & -0.2 & 0.1 & -0.6 & -0.5 & 12 \\
T3 & 0.1 & -0.2 & 0.2 & -0.5 & -0.5 & 12 \\
T4 & 0.1 & -0.3 & 0.1 & -0.7 & -0.7 & 11 \\
T5 & 1.0 & -0.3 & 0.1 & 0.7 & \\
\hline
\end{tabular}

* PES: Pink Esthetic Score; negative values show increase the soft tissue/bone levels compared to the baseline.

Evaluation of the bone levels around the implant revealed an overall gain of $0.7 \mathrm{~mm}$ on the mesial and distal aspects between implant placement and 10-year follow-up (Table 1).

The results from the CBCT and intraoral scan superimposition were interpreted from the midfacial cross-section of the implant (Figure 5). The facial bone extended $2.1 \mathrm{~mm}$ above the implant shoulder in a coronal direction and the height of the soft tissue was $5.4 \mathrm{~mm}$ when measured from the implant shoulder. The mean thickness of facial bone and soft tissue around the implant was 1.45 and $1.3 \mathrm{~mm}$, respectively (Table 2).

Table 2. Facial bone and soft tissue thickness (in $\mathrm{mm}$ ) around implant at $\mathrm{T} 5$ time point.

\begin{tabular}{cccccc}
\hline & Implant Shoulder & $\mathbf{1 ~} \mathbf{~ m m}$ & $\mathbf{2} \mathbf{~ m m}$ & $\mathbf{4} \mathbf{~ m m}$ & Mean Thickness \\
\hline Bone & 1.7 & 1.5 & 1.5 & 1.1 & 1.45 \\
Soft tissue & 1.1 & 1.1 & 1.2 & 1.8 & 1.3 \\
Combined tissue thickness & 2.8 & 2.6 & 2.7 & 2.9 & 2.75 \\
\hline
\end{tabular}

\section{Discussion}

This case report documents the clinical outcomes of an immediately placed and restored implant in the anterior maxilla over a long-term follow-up period. After 10 years in function, no biological and prosthetic complications were observed related to the single implant in the maxillary left central incisor region.

Evaluation of 2-dimensional radiographs showed that the peri-implant bone levels improved by $0.7 \mathrm{~mm}$ over the 10-year follow-up period. An overall gain in bone levels around immediate implants has been reported previously in the literature [3,5,8]. Evaluation of the bone levels on the final follow-up CBCT revealed facial bone thickness of $1.70 \mathrm{~mm}$ at the level of the implant platform at the 10-year follow-up. These results are similar when compared to a mean facial bone thickness of $2.31 \mathrm{~mm}$ reported by a recent study evaluating 
45 patients with immediate implant placement after 12-month follow-up [9]. Interestingly, patients with labial bone defects were included in the abovementioned study which was not the case with our study. It should be taken into account that the other study reports a very short follow-up period of one year which makes it difficult to compare the results. Nonetheless, this emphasizes the importance of appropriate case selection when it comes to immediate implant placement in the anterior maxilla.

Levels of midfacial mucosal margin remained stable throughout the 10-year period. Soft tissue recession has been considered to be unpredictable around immediate implants according to a few studies [10-12], whereas other studies have reported stable mucosal margins after immediate placement $[5,13,14]$. When considering the papillae, the distal papilla levels remained stable whereas a recession of $1 \mathrm{~mm}$ was observed at the mesial papilla. Most of this recession was observed after five years in function. This may have been the result of changes in the level of interproximal bone on the adjacent central incisor.

Aesthetic outcomes as evaluated using the Pink Esthetic Score were satisfactory after 10 years in function. The IPR technique has been reported to preserve the peri-implant soft tissues during the healing phase with the aid of a provisional restoration thereby leading to satisfactory aesthetic outcomes $[3,15,16]$. All of the individual variables remained stable after the definitive crown insertion in this study except for the mesial papilla, which showed a slight deterioration between five and 10-year follow-up. Alveolar process contour has been reported to deteriorate after immediate placement in previous studies despite improved overall PES scores $[5,17,18]$. Some authors have advocated for the use of a connective tissue graft to counteract this shrinkage [18]. Although a slight deterioration of alveolar contour was observed in this study between implant placement and definitive crown insertion, the overall contour remained stable throughout the subsequent 10-year follow-up. Indeed, the final follow-up CBCT showed a mean midfacial soft and hard tissue thickness of $2.75 \mathrm{~mm}$.

This case report emphasizes the importance of appropriate case selection and accurate 3-dimensional implant positioning in the overall clinical and aesthetic outcome of immediately placed and restored implants in the anterior maxilla. Application of specific case selection criteria of intact socket wall and absence of gingival pathology, as well as standardized treatment protocol of flapless implant placement and grafting of the implantbone gap led to satisfactory aesthetic outcomes and minimal hard and soft tissue changes over a 10-year follow-up period.

\section{Conclusions}

Appropriate case selection and a standardized treatment protocol are key to favorable success rates and optimal soft and hard tissues outcomes around immediately placed and restored implants in the long term.

Author Contributions: Conceptualization, H.A. and S.I.; software, H.A.; writing-original draft preparation, H.A.; writing-review and editing, S.I. Both authors have read and agreed to the published version of the manuscript.

Funding: This research received no external funding.

Institutional Review Board Statement: Not applicable.

Informed Consent Statement: Informed consent was obtained from the subject involved in this study.

Conflicts of Interest: The authors declare no conflict of interest.

\section{References}

1. Esposito, M.; Grusovin, M.G.; Polyzos, I.P.; Felice, P.; Worthington, H.V. Interventions for replacing missing teeth: Dental implants in fresh extraction sockets (immediate, immediate-delayed and delayed implants). Cochrane Database Syst. Rev. 2010, CD005968. [CrossRef] [PubMed]

2. Den Hartog, L.; Huddleston Slater, J.J.; Vissink, A.; Meijer, H.J.; Raghoebar, G.M. Treatment outcome of immediate, early and conventional single-tooth implants in the aesthetic zone: A systematic review to survival, bone level, soft-tissue, aesthetics and patient satisfaction. J. Clin. Periodontol. 2008, 35, 1073-1086. [CrossRef] [PubMed] 
3. Khzam, N.; Arora, H.; Kim, P.; Fisher, A.; Mattheos, N.; Ivanovski, S. Systematic Review of Soft Tissue Alterations and Esthetic Outcomes Following Immediate Implant Placement and Restoration of Single Implants in the Anterior Maxilla. J. Periodontol. 2015, 86, 1321-1330. [CrossRef] [PubMed]

4. Lang, N.P.; Pun, L.; Lau, K.Y.; Li, K.Y.; Wong, M.C. A systematic review on survival and success rates of implants placed immediately into fresh extraction sockets after at least 1 year. Clin. Oral Implants Res. 2012, 23 (Suppl. 5), 39-66. [CrossRef] [PubMed]

5. Arora, H.; Khzam, N.; Roberts, D.; Bruce, W.L.; Ivanovski, S. Immediate implant placement and restoration in the anterior maxilla: Tissue dimensional changes after 2-5 year follow up. Clin. Implant Dent. Relat. Res. 2017, 19, 694-702. [CrossRef] [PubMed]

6. Buser, D.; Martin, W.; Belser, U.C. Optimizing esthetics for implant restorations in the anterior maxilla: Anatomic and surgical considerations. Int. J. Oral Maxillofac. Implant 2004, 19 (Suppl. 7), 43-61.

7. Fürhauser, R.; Florescu, D.; Benesch, T.; Haas, R.; Mailath, G.; Watzek, G. Evaluation of soft tissue around single-tooth implant crowns: The pink esthetic score. Clin. Oral Implant Res. 2005, 16, 639-644. [CrossRef] [PubMed]

8. Noelken, R.; Moergel, M.; Kunkel, M.; Wagner, W. Immediate and flapless implant insertion and provisionalization using autogenous bone grafts in the esthetic zone: 5-year results. Clin. Oral Implant Res. 2018, 29, 320-327. [CrossRef] [PubMed]

9. Liu, R.; Yang, Z.; Tan, J.; Chen, L.; Liu, H.; Yang, J. Immediate implant placement for a single anterior maxillary tooth with a facial bone wall defect: A prospective clinical study with a one-year follow-up period. Clin. Implant Dent. Relat. Res. 2019, 21, 1164-1174. [CrossRef] [PubMed]

10. Chen, T.S.; Buser, D. Esthetic outcomes following immediate and early implant placement in the anterior maxilla-A systematic review. Int. J. Oral Maxillofac. Implant 2014, 29, 186-215. [CrossRef] [PubMed]

11. Kan, J.Y.K.; Rungcharassaeng, K.; Lozada, J.L.; Zimmerman, G. Facial gingival tissue stability following immediate placement and provisionalization of maxillary anterior single implants: A 2- to 8-year follow-up. Int. J. Oral Maxillofac. Implant 2011, 26, 179-187.

12. Seyssens, L.; Eghbali, A.; Cosyn, J. 10-year prospective study on single immediate implants. J. Clin. Periodontol. 2020, 47, 1248-1258. [CrossRef] [PubMed]

13. Fürhauser, R.; Mailath-Pokorny, G.; Haas, R.; Busenlechner, D.; Watzek, G.; Pommer, B. Immediate Restoration of Immediate Implants in the Esthetic Zone of the Maxilla Via the Copy-Abutment Technique: 5-Year Follow-Up of Pink Esthetic Scores. Clin. Implant Dent. Relat. Res. 2017, 19, 28-37. [CrossRef] [PubMed]

14. Arora, H.; Ivanovski, S. Immediate and early implant placement in single-tooth gaps in the anterior maxilla: A prospective study on ridge dimensional, clinical, and aesthetic changes. Clin. Oral Implant Res. 2018, 29, 1143-1154. [CrossRef] [PubMed]

15. Arora, H.; Ivanovski, S. Clinical and aesthetic outcomes of immediately placed single-tooth implants with immediate vs. delayed restoration in the anterior maxilla: A retrospective cohort study. Clin. Oral Implant Res. 2018, 29, 346-352. [CrossRef] [PubMed]

16. Arora, H.; Ivanovski, S. Correlation between pre-operative buccal bone thickness and soft tissue changes around immediately placed and restored implants in the maxillary anterior region: A 2-year prospective study. Clin. Oral Implant Res. 2017, 28, 1188-1194. [CrossRef] [PubMed]

17. Noelken, R.; Oberhansl, F.; Kunkel, M.; Wagner, W. Immediately provisionalized OsseoSpeed Profile implants inserted into extraction sockets: 3-year results. Clin. Oral Implant Res. 2016, 27, 744-749. [CrossRef] [PubMed]

18. Cosyn, J.; Eghbali, A.; Hermans, A.; Vervaeke, S.; De Bruyn, H.; Cleymaet, R. A 5-year prospective study on single immediate implants in the aesthetic zone. J. Clin. Periodontol. 2016, 43, 702-709. [CrossRef] [PubMed] 